Agro-Science Journal of Tropical Agriculture, Food, Environment and Extension Volume 20 Number 3 (July 2021) pp. $110-113$

ISSN 1119-7455

SHORT COMMUNICATION

\title{
RELATIONSHIPS BETWEEN BODY WEIGHT AND SOME LINEAR MORPHOMETRIC TRAITS IN NIGERIAN NSUKKA ECOTYPE LOCAL HENS
}

\author{
*Ikeh N.E. and Okwesili O.R. \\ Department of Animal Science, University of Nigeria, Nsukka, Nigeria \\ *Corresponding author's email: nnanna.ikeh@unn.edu.ng
}

\begin{abstract}
Body weight (BW) and linear body measurements of 120 Nigerian Nsukka ecotype local hens in terms of body length (BL), chest girth (CG), thigh circumference (TC), thigh length (TL), and shank length (SL) were taken and subjected to Pearson correlation analysis to obtain the relationship between these growth traits. Multiple Linear Stepwise Regression procedure was used to find the best linear combination of the linear body measurements that can best predict $B W$. The findings showed that linear body measurement traits of Nigerian heavy ecotype local hens were strongly $(p<0.01)$ and positively correlated $(0.5<r)$ except thigh length which recorded a moderate value $(0.3<r>0.5)$. The regression equations of linear body measurement traits with $B W$ were positive with coefficient of determination ranging from $60.5-74.6 \%$. The stepwise analyses showed shank length as best single measurement with $R^{2}=0.605$, while inclusion of our five predictors in an equation resulted in $R^{2}=0.746$. Thus, the following equation was generated: $B W=-1485.70+82.06 S L+$ $58.34 \mathrm{BL}+38.70 \mathrm{TC}+8.39 \mathrm{CG}+3.85 \mathrm{TL}$. This showed that they accounted for $74.6 \%$ of the variations in the $B W$ of Nigerian heavy ecotype local hens. The prediction equations generated from linear body measurement traits are positive and strong, therefore can accurately be employed to predict the relative $B W$ of Nigerian heavy ecotype local hens during selection programs as well as in the market with the use of measuring tape.
\end{abstract}

Key words: body measurements, body weight, Nsukka ecotype, correlation, regression

\section{INTRODUCTION}

The Nigerian Nsukka ecotype local chicken is one of the numerous indigenous genetic resources among poultry that can be found in almost every community in Nigeria. These indigenous poultry resources which have adapted to a wide range of ecological settings present viable alternatives to smallholder poultry production in developing countries (Daikwo et al., 2015). This has led to efforts by researchers to employ scientific tools in improving the Nigerian heavye local chicken (Nwosu et al., 1985; Momoh and Kershima, 2008; Ndofor-Foleng et al., 2010; 2015, Oleforuh-Okoleh et al., 2012; Agbo et al., 2018; Ikeh et al., 2020). Genetic improvements through breeding programmes have enabled breeders improve the performance of indigenous chicken (Agbo et al., 2018) and body weight $(\mathrm{BW})$ represents a vital economic trait breeders want to select (Tyasi et al., 2017). BW is significant for any selection and breeding program, feeding, vaccination, and Drug dosage in animal production (Tyasi et al., 2020).

The relationship between BW and other linear body measurements has been described to have important implications. Hence, the success of a breeding program relies on the ability to establish relationships that exist between identified traits (Tyasi et al., 2020). BW is used in ascertaining the growth rate of an animal and its price during marketing. Prospective customers and farmers often use visual appraisal which may not be accurate as the weighing scale is not always available. Multiple Linear Regression is an available tool for estimating relationships among variables, as well as predicting one variable from another. Researches have shown that linear body measurement traits are good predictor of BW in different chicken genotypes such as Senegal Indigenous chicken (Gueye et al., 1998), Chinese indigenous Dagor chickens (Tyasi et al., 2017), Ugandan indigenous chickens (Semakula et al., 2011) and two commercial meat type (Ross and Anak Titan) chicken genotypes (Ajayi et al., 2008). Because body conformation is different among breeds of chickens, different coefficients and exponents are needed for different breeds of chickens. Therefore, this study aimed at developing equations to estimate BW of Nigerian heavy ecotype local hens using linear body measurements taken.

\section{MATERIALS AND METHODS}

The study was carried out at the Poultry Unit of the Department of Animal Science Teaching and Research Farm, University of Nigeria, Nsukka. The study lasted for twelve weeks. The experimental procedures complied with the provisions of the University of Nigeria, Nsukka Ethical Committee on the Use of Animals for Biometric Research. 


\section{Animals and Data Collection}

In total, 120 individuals between 50 to 56 days of age were obtained randomly from the $8^{\text {th }}$ generation population of Nigerian heavy local chicken ecotype, kept at the Department of Animal Science Local Chicken Research Unit, University of Nigeria Nsukka. The animals were housed individually on labeled metal cages and intensively managed. These birds were raised in the same chicken house and fed the same commercial growers mash with crude protein: $19.8 \%$; fat: $3.6 \%$; crude fiber: $4.2 \%$; calcium: $4.2 \%$; available phosphorus: $0.5 \%$; methionine: $0.45 \%$; lysine: $0.85 \%$ and metabolizable energy of $2880 \mathrm{kCal} \mathrm{kg}^{-1}$.

The following traits were measured on weekly basis: BW was measured with a weighing scale in kilogrammes; body length (BL) was measured as the distance from the base of the neck to the cloaca using a measuring tape in centimeters; chest girth (CG) was taken when a measuring tape is looped around the region of the breast under the wing; shank length (SL) was recorded as the length of tarso-metatarsus from the hock joint to the metatarsal pad using a measuring tape; thigh length (TL) was recorded as the length from tibia-femur joint to the tibia-tarsus joint; thigh circumference (TC) was measured as the circumference of the middle thigh. All the measurements were collected with the same person to avoid individual variations on measuring.

\section{Statistical Analysis}

Pearson correlation and Stepwise regression procedure of SPSS statistical package was used to find the best linear combination of linear traits measured that can best predict the BW. The multiple linear regression model adopted was:

$$
\mathrm{Y}=\mathrm{a}+\mathrm{b}_{1} \mathrm{X}_{1}+\mathrm{b}_{2} \mathrm{X}_{2}+\mathrm{b}_{3} \mathrm{X}_{3}+\mathrm{b}_{4} \mathrm{X}_{4}+\mathrm{b}_{5} \mathrm{X}_{5}
$$

where $Y$ is dependent or endogenous variable (BW); $a$ is intercept; $b$ 's is regression coefficients; $X$ 's is independent or exogenous variables (BL, CG, TL, TC, SL). Comparison of regression equations were based on the coefficient of determination. $\left(R^{2}\right)$.

\section{RESULTS AND DISCUSSION}

The Pearson correlation coefficients among BW and other linear body measurement traits of Nigerian Nsukka ecotype local hens are presented in Table 1.

The coefficients showed that BW had significant linear relationship with $\mathrm{BL}, \mathrm{CG}$, thigh circumference, thigh length, and shank length. The directions of the relationships were shown to be positive as shank length had the highest coefficient values while thigh length had the least coefficient values. The magnitude or strength of the association between $\mathrm{BW}$ and other linear body measurement traits were strong $(0.5<r)$ except thigh length which recorded a moderate $(0.3<r>0.5)$ relationship. Our results indicated that other linear body measurement traits were significantly associated with each other in a strong and positive direction with thigh length being the only trait with moderate association with other traits evaluated in this study. The results of this current study are similar to the early results reported in various studies of indigenous chickens (Gueye et al., 1998; Yang et al., 2006; Mancha et al., 2008; Yakubu and Salako, 2009; Sri Rachma et al., 2013; Egena et al., 2014). These authors observed that BWs were highly related to all the other linear body measurements of the chickens with increases in any of the body measurements will definitely lead to a corresponding increase in the BW of the chickens. They all further concluded that the strong correlation between $\mathrm{BW}$ and other linear body measurements were useful as selection criterion.

Moreover, Momoh and Kershima (2008) confirmed the reports of Ige et al. (2006) that higher muscle deposition in breast and thigh created a strong relationship between breast circumference or shank length with live weight. Based on the fact that most linear measurements reflect primarily the length of the bones of animals. Oke et al. (2004) and Abdullah et al. (2010) explained that durable correlation was indicated between shank length and body length, and body girth and body length are also indications that shank length and body girth could be used as indicators of body length. And yet, clear relation between body girth and shank length could be used complimentarily in selection (Momoh and Kershima, 2008). If the explicit phenotypic relation translates into positive genetic relation thus, selection for one will improve other as a correlated response (Apuno et al., 2011). It is very important to consider the relationship between BW and body measurement traits as this could be useful as a selection criterion to improve the BW. Hence, regression analysis was performed to develop predictive equations for the estimation of BW using linear body measurement traits which had positively significant correlation with BW.

The stepwise regression analyses for the best linear combinations of linear body measurement traits for predicting BW of Nigerian heavy ecotype local hens are presented in Table 2. The results showed that the predictors significantly $(p<0.01)$ predicted BW of Nigerian heavy ecotype local hens with good efficiencies $\left(R^{2}=60.5-74.6 \%\right)$.

Table 1: Pearson correlations among body weight and other linear body measurement traits of Nigerian heavy ecotype local hens

\begin{tabular}{lllllll}
\multicolumn{6}{l}{ Table 1: Pearson correlations among body weight and other linear body } & measurement traits of Nigerian heavy ecotype local hens \\
\hline Trait & BW & BL & CG & TC & TL & SL \\
\hline BW & - & & & & \\
BL & $0.733^{* *}$ & - & & & \\
CG & $0.736^{* *}$ & $0.616^{* *}$ & - & - & \\
TC & $0.746^{* *}$ & $0.605^{* *}$ & $0.728^{* *}$ & - & \\
TL & $0.464^{* *}$ & $0.368^{* *}$ & $0.454^{* *}$ & $0.420^{* *}$ & - \\
SL & $0.778^{* *}$ & $0.630^{* *}$ & $0.757^{* *}$ & $0.735^{* *}$ & $0.441^{* *}$ & - \\
\hline BW - body weight; & SL - shank length; BL - body length; TC - thigh circumference; CG - chest girth; TL - thigh length; ** - significant at $p<0.01$
\end{tabular}


The analysis built a model with 5 steps, each of which adds a predictor to the equation. The best single measurement was shank length with an $R^{2}=$ 0.605 . While more predictors are added, the adjusted $r$-square levels off; adding a second predictor to the first raises it with 0.097 (Table 2) but adding a fifth predictor to the previous four only results in a 0.008 -point increase. Our final $R^{2}$ $=0.746$, which means that our 5 predictors accounted for $74.6 \%$ of the variance in the BW of Nigerian heavy ecotype local hens. Our final model states that $\mathrm{BW}=-1485.70+82.06 \mathrm{SL}+58.34 \mathrm{BL}$ $+38.70 \mathrm{TC}+8.39 \mathrm{CG}+3.85 \mathrm{TL}$ with our strongest predictor being SL $(b=82.06)$. SL is the body part that is commonly measured in poultry to relate to $\mathrm{BW}$. A linear relationship between $\mathrm{BW}$ and SL in one breed of chicken was first reported by Lerner (1937). Because body conformation (especially chest girth) is different among breeds of chickens, different coefficients and exponents are needed for different breeds of chickens. For livestock, it is more common to estimate weight by measuring a part of the body trunk rather than an extremity. A good estimate of weight can be obtained by measuring the heart girth, the circumference of the animal posterior to the front legs. This estimate is routine for cattle, horses, and swine (Latshaw and Bishop, 2001). The significant positive correlations among the body measurements observed in the Nigerian heavy ecotype local hens indicate high predictability among the variables (Pundir et al., 2011). This is in line with the work of Petrus et al. (2019) who showed a strong relationship between linear body measurements and BW in female Boschveld chicken. Also, for the Japanese quail, Ojo et al. (2014) reported estimates of coefficient of determination and predictive equations which showed that BW in this quail is linearly related to body measurements especially with body girth and body length. They concluded that breeders could use body girth and body length as criteria for assessment and early selection of Japanese quail the smallest farmed avian species for BW.

Furthermore, one of the purposes of assessing the interrelationship between performance parameters and BW and its associated traits like body dimensions, is predicting $\mathrm{BW}$ in indigenous chickens where scientific scales are not available. Momoh and Kershima (2008) developed both linear and multiple regression as predictors of BW in Nigerian local chickens, and found out that in both sexes the multiple regression equations when compared with the simple linear regression equations, multiple regression technique was better in predicting $\mathrm{BW}$ from linear body measurements than simple linear regression technique. Multiple regression analysis has been used to interpret the complex relationship among $\mathrm{BW}$ and some linear body measurements (Yakubu et al., 2012).

Ukwu et al. (2014) performed a statistical modeling of BW and linear body measurements in Nigerian indigenous chicken, the resultant predictive equations showed that there were significant relationships between $\mathrm{BW}$ and linear body measurements. The high $\mathrm{R}^{2}$ values observed showed that the predictive equations could be used to predict $\mathrm{BW}$ accurately, with the multiple regression model being more efficient than the simple regression models. Wolanski et al. (2006) suggested that due to the positive and strong nature of the correlation between BW and linear body measurement traits in males of eight selected pure or commercial broiler breeder strains, it means that BW could be estimated from body measurements. From the results of Machebe and Ezekwe (2010), BW of pigs can be estimated using simple linear body measurement of heart girth, body length and flank-to-flank. This is because growth in animals could be evaluated from the component parts of the animal. This implies that improvements in the body measurements will invariably lead to a corresponding improvement in the $\mathrm{BW}$ of the indigenous Nigerian chickens especially if the correlation is positive (Egena et al., 2014). Ogah (2011) suggested that prediction based on single linear body measurements is unreliable, therefore a crucial step in constructing a multiple regression model for predictive purposes is to determine those variables that contribute much to the response variable (BW) with elimination of non-significant variables. Using all possible selection approach will maximize the number of independent variables (BL, CG, TC, TL and SL) and their contribution in regression equation for predicting the dependent variable.

\section{CONCLUSION}

In conclusion, the findings suggest that there is a relationship between body weight (BW) and linear body morphometric traits. The BW had significant relationships with linear body measurement traits. Also, the BW of Nigerian heavy ecotype local hens could be predicted accurately from shank length, back length, thigh circumference and chest girth. Our findings might help the recognition of the association between BW and linear body measurement traits in these local hens, and this could selection to improve BW in breeding. Further studies in this regard are needed with larger sample of the same or closely related local chicken breeds.

Table 2: Stepwise regression for the combination of linear traits for predicting body weight of Nigerian heavy ecotype local hens

\begin{tabular}{llll}
\hline Predicator & Prediction equation & $\mathrm{R}^{2}$ & Adjusted $R^{2}$ \\
\hline SL & $\mathrm{BW}=-454.93+221.60 \mathrm{SL}$ & $0.605^{* *}$ & 0.604 \\
SL, BL & $\mathrm{BW}=-1689.96+149.25 \mathrm{SL}+75.83 \mathrm{BL}$ & $0.702^{* *}$ & 0.701 \\
SL, BL, TC & $\mathrm{BW}=-1535.15+103.3 \mathrm{SL}+63.73 \mathrm{BL}+48.84 \mathrm{TC}$ & $0.735^{* *}$ & 0.733 \\
SL, BL, TC, CG & $\mathrm{BW}=-1515.55+85.12 \mathrm{SL}+59.32 \mathrm{BL}+40.00 \mathrm{TC}+9.30 \mathrm{CG}$ & $0.743^{* *}$ & 0.741 \\
SL, BL, TC, CG, TL & $\mathrm{BW}=-1485.70+82.06 \mathrm{SL}+58.34 \mathrm{BL}+38.70 \mathrm{TC}+8.39 \mathrm{CG}+3.85 \mathrm{TL}$ & $0.746^{* *}$ & 0.744 \\
\hline
\end{tabular}

BW - body weight, SL - shank length, BL - body length, TC - thigh circumference, CG - chest girth, TL - thigh length, $R^{2}$ - coefficient of regression, ${ }^{* *}$ Significant at $p<0.01$ 


\section{REFERENCES}

Abdullah A.Y., Al-Beitawi N.A., Rjoup M.M., Qudsieh R.I. and Ishmais M.A. (2010). Growth performance, carcass and meat quality characteristics of different commercial crosses of broiler strains of chicken. $J$. Poult. Sci., 47 (1), 13-21

Agbo M.C., Udeh F.U., Ndofor-Foleng H.M. Ohagenyi I.J. and Nwosu C.C. (2018). Genetic progress of the production traits in the Nigerian heavy local chicken ecotype obtained by selection index in the Derived Savannah Zone of Nigeria. Proc. $23^{\text {rd }}$ Ann. Conf. Anim. Sci. Assoc. Nig. (ASAN), Ilorin-Nigeria. pp. 105-108

Ajayi F.O., Ejiofor O. and Ironkwe M.O. (2008). Estimation of body weight from linear body measurements in two commercial meat-type chicken. Glob. J. Agric. Sci., 7 (1), 57-59

Apuno A.A., Mbap S.T. and Ibrahim T. (2011). Characterization of local chickens (Gallus gallus domesticus) in Shelleng and Song Local Government Areas of Adamawa State, Nigeria. Agric. Biol. J. N. Am., 2 (1), 6-14

Daikwo S.I., Dike U.A. and Dim N.I. (2015). Discriminant analysis of morphometric differences in the normal feathered and frizzle feathered chickens. Agro-Science, 14 (3), 12-15

Egena S.S.A., Ijaiya A.T. and Kolawole R. (2014). An assessment of the relationship between body weight and body measurements of indigenous Nigeria chickens (Gallus gallus domesticus) using path coefficient analysis. Livest. Res. Rural Dev., 26, 29-33

Gueye E.F., Ndiaye A. and Branckaert R.D.S. (1998). Prediction of body weight on the basis of body measurements in mature indigenous chickens in Senegal. Livest. Res. Rural Dev. 10, 320-325

Ige A.O., Akinlade J.A., Ojedapo L.O., et al. (2006). Effect of sex on interrelationship between body weight and linear body measurements of commercial broilers in a derived savannah environment of Nigeria. Proc. $11^{\text {th }}$ Ann. Conf. Anim. Sci. Assoc. Nig., pp. 18-21

Ikeh N.E., Ndofor-Foleng H.M., Nnajiofor N.W., et al. (2020). Association of ovocleidin-116 polymorphisms with egg quality traits of Nigerian heavy local chicken ecotype reared in derived savannah. Nig. J. Anim. Sci., 22 (1), 74-82

Latshaw J.D. and Bishop B.L. (2001). Estimating body weight and body composition of chickens by using non invasive measurements. Poult. Sci., 80, 868-873. DOI: $10.1093 / \mathrm{ps} / 80.7 .868$

Lerner I.M. (1937). Shank length as a criterion of inherent size. Poult. Sci., 16, 213-215

Machebe N.S and Ezekwe A.G. (2010). Predicting body weight of growing-finishing gilts raised in the tropics using linear body measurements. Asian J. Exp. Biol. Sci., 1 (1), 162-165

Mancha Y.P., Mbap S.T. and Abdul S.D. (2008). An assessment of observable and measurable traits as possible indices of live weight in local chickens on the Jos Plateau of Nigeria. Nig. Poult. Sci. J., 5, 3-10

Momoh O.M. and Kershima D.E. (2008). Linear body measurements as predictors of body weight in Nigerian local chickens. ASSET (Series A), 8 (2), 206-212

Ndofor-Foleng H.M., Ngongeh L.A., Uberu C.P.N. and Nwosu C.C. (2010). Evaluation of the performance of two local chicken and the main cross ecotypes reared in Nsukka, Enugu State, Nigeria. Int. J. Sci., Nature, 1 (2), 179-182

Ndofor-Foleng H.M., Oleforuh-Okoleh V., Musongong G.A., Ohageni J. and Duru U.E. (2015). Evaluation of growth and reproductive traits of Nigerian local chicken and exotic chicken. Indian J. Anim. Res., 49 (2), 155-160
Nwosu C.C., Gowen F.A., Obioha F.C., Akpan I.A. and Onuora G.I. (1985). A biometrical study of the conformation of the native chicken. Nig. J. Anim. Prod., 12 (1\&2), 141-146

Ogah D.M. (2011). Assessing size and conformation of the body of Nigerian indigenous turkey. Slovak. $J$. Anim. Sci., 44 (1), 21-27

Ojo V., Fayeye T.R., Ayorinde K.L. and Olojede H. (2014). Relationship between body weight and linear body measurements in Japanese quail. J. Sci. Res., 6, 175-183

Oke U.K., Herbert U. and Nwachukwu E.N. (2004). Association between body weight and some egg production traits in the guinea fowl (Numida meleagris galeata pallas). Livest. Res. Rural Dev., 16 (9), http://www.lrrd.org/lrrd16/9/oke16072.htm

Oleforuh-okoleh V., Nwosu C.C., Adeolu A.I., Udeh I., Uberu C.P.N. and Ndofor-Foleng, H.M. (2012). Egg production performance in a Nigerian local chicken ecotype subjected to selection. J. Agric. Sci., 4 (6), 180-186

Petrus N.P., Kangootui K., Kandiwa E., Madzingira O. and Mushonga O. (2019). Relationship of age and live weight to linear body traits in female intensively reared boschveld chicken in Namibia. Int. J. Poult. Sci., 18, 483-491

Pundir R.K., Singh P.K. and Dangi P.S. (2011). Factor analysis of biometric traits of kankrej cows to explain body conformation. Asian-Austra. J. Anim. Sci., 24 (4), 449-456

Semakula J., Lusembo P., Kugonzam D.R., et al. (2011). Estimation of live body weight using zoometrical measurements for improved marketing of indigenous chicken in the Lake Victoria Basin of Uganda. Livest. Res. Rural Dev., 23 (8). http://www.lrrd.org/ $\operatorname{lrd} 23 / 8 /$ sema23170.htm

Sri Rachma A.B., Hiroshi H., Mumihsan A.D., Lellah R. and Kusumandari I.P. (2013). Study of body dimension of Gaga' chicken, germ plasm of local chicken from South Sulawesi-Indonesia. Int. J. Plan. Anim. Environ. Stud., 3, 204-209

Tyasi T.L., Makgowo K.M., Mokoena K., et al. (2020). Classification and regression tree (CRT) analysis to predict body weight of Potchefstroom koekoek laying hens. Adv. Anim. Vet. Sci., 8 (4), 354-359

Tyasi T.L., Qin N., Jing Y., et al. (2017). Assessment of relationship between body weight and body measurement traits of indigenous Chinese Dagu chickens using path analysis. Indian J. Anim. Res., 51 (3), 588-593

Ukwu H.O., Okoro V.M.O. and Nosike R.J. (2014). Statistical modelling of body weight and linear body measurements in Nigerian indigenous chicken. IOSR J. Agric. Vet. Sci. 7 (1), 27-30

Wolanski N.J., Renema R.A., Robinson F.E., Carney V.L. and Fanchert, B.I. (2006). Relationship between chick conformation and quality measures with early growth traits in males of eight selected pure or commercial broiler breeder strains. Poult. Sci., 85, 1490-1497

Yakubu A. and Salako A.E. (2009). Path coefficient analysis of body weight and morphological traits of Nigerian indigenous chickens. Egyptian Poult. Sci., 29, 837-850

Yakubu A., Okunsebor S.A., Kiqbu A.A., Sotolu A.O. and Imqbian T.D. (2012). Use of factor scores for predicting body weight from some morphometric measurements of two fish species in Nigeria. J. Agric. Sci. 4 (1), 60-64

Yang Y., Mekki M.D., Lu S.J., et al. (2006). Canonical correlation analysis of body weight, body measurements and carcass characteristics of Jinghai vellow chicken. J. Anim. Vet. Adv., 5, 980-984 